\title{
Editorial: Photocatalysis for Environmental Applications
}

\author{
Fan Dong ${ }^{1,2 *}$, Yuxin Zhang ${ }^{3 *}$ and Sen Zhang ${ }^{4 *}$ \\ ${ }^{1}$ Chongqing Key Laboratory of Catalysis and New Environmental Materials, Engineering Research Center for Waste Oil \\ Recovery Technology and Equipment of Ministry of Education, College of Environment and Resources, Chongqing \\ Technology and Business University, Chongqing, China, ${ }^{2}$ Research Center for Environmental Science \& Technology, Institute \\ of Fundamental and Frontier Sciences, University of Electronic Science and Technology of China, Chengdu, China, ${ }^{3}$ College \\ of Materials Science and Engineering, Chongqing University, Chongqing, China, ${ }^{4}$ Department of Chemistry, University of \\ Virginia, Charlottesville, VA, United States
}

Keywords: photocatalysis, environmental catalysis, air pollution, reaction mechanism, nanomaterials

\section{Editorial on the Research Topic}

\section{Photocatalysis for Environmental Applications}

Environmental pollution is one of the major challenges because of the rapid development of urbanization and industrialization. Considering this environmental challenge, providing a clean environment for human beings is very important for the sustainability. The nanostructured photocatalysts with intriguing physiochemical property have offered opportunities to solve the issue of environmental sustainability (Chen et al., 2019; Huo et al., 2019; Li J. et al., 2019). In recent years, significant advances have been witnessed on the synthesis and application of photocatalyst in environmental remediation (He et al., 2018a; Li et al., 2018c; Li X. et al., 2018, 2019; Wang et al., 2018c). These new photocatalysts have enabled wide applications in the air purification, wastewater treatment, and so on (Cui et al., 2018; He et al., 2018b; Li et al., 2018b; Xiong et al., 2018) The rapid development in catalysis science, nanoscience, and materials enable the significant advances in new strategies for the controlled preparation, photocatalysis reaction mechanism, and structure-activity relationship of photocatalysts (Dong et al., 2018a; Li et al., 2018a; Wang et al., 2018a,b). The structural features of photocatalysts can be further tuned to achieve enhanced photocatalytic performance in environmental applications (Dong et al., 2018b; Li X. et al., 2018; Wang et al., 2018d).

The rapid development in photocatalysis for environment has inspired this interesting Research Topic. We have invited scientists worldwide to contribute original research and review articles which could enhance our understanding of the key problems in environmental applications of nanostructured photocatalysts. The original articles describing the photocatalysts for environmental control, and for sustainable development have been accepted for publication after peered review. In this topic issue, the readers will find very interesting results covering the following aspects (1) design and synthesis of photocatalysts with new morphology and active catalytic sites; (2) photocatalysts for green synthesis; (3) photocatalysts for $\mathrm{CO}_{2}$ conversion to solar fules; (4) photocatalysts for wastewater treatment and air purification; and (5) revealing the photocatalysis reaction mechanism as applied in environmental problems.

For the $\mathrm{g}-\mathrm{C}_{3} \mathrm{~N}_{4}$ based photocatalysts, Guan et al. synthesized $\mathrm{Ti}_{4} \mathrm{O}_{7} / g-\mathrm{C}_{3} \mathrm{~N}_{4}$ composites by a low temperature method. The enhanced photocatalytic activity for $\mathrm{Ti}_{4} \mathrm{O}_{7} / g-\mathrm{C}_{3} \mathrm{~N}_{4}$ could be ascribed to the promoted charge separation and photoabsorption efficiency. Yang et al. fabricated a monolithic g- $\mathrm{C}_{3} \mathrm{~N}_{4}$ /melamine sponge by a cost-effective ultrasonic-coating method. The monolithic g- $\mathrm{C}_{3} \mathrm{~N}_{4}$ /melamine demonstrated high photocatalytic activity for $\mathrm{NO}$ removal and $\mathrm{CO}_{2}$ reduction. Guan et al. prepared the $\mathrm{Ti}_{4} \mathrm{O}_{7} / g-\mathrm{C}_{3} \mathrm{~N}_{4}$ photocatalysts by a hydrolysis method. The $\mathrm{Ti}_{4} \mathrm{O}_{7} / g-\mathrm{C}_{3} \mathrm{~N}_{4}$ exhibited remarkably improved photocatalytic activity for hypophosphite oxidation, which can be 
ascribed to the heterojunction structure of $\mathrm{Ti}_{4} \mathrm{O}_{7} / \mathrm{g}_{-} \mathrm{C}_{3} \mathrm{~N}_{4}$ that enhanced charge carrier efficiency (Guan et al.).

$\mathrm{Xu}$ et al. prepared $\mathrm{BiVO}_{4}$ by a facile method and conducted a trapping experiment to study the free radical transformation mechanisms. They identified $\bullet \mathrm{OH}$ and $\mathrm{h}^{+}$as the main active radicals for oxidation. Han et al. developed a new photoelectrochemical (PEC) technology for simultaneous $\mathrm{SO}_{2}$ removal and $\mathrm{H}_{2}$ production. The enhanced $\mathrm{H}_{2}$ production and $\mathrm{SO}_{2}$ removal efficiency can be attributed to the improved charge carrier transfer after Mo doping (Han et al.). Regmi et al. reviewed recent advances on the microbial decontamination by photocatalysts and their possible mechanisms are highlighted.

Cui et al. fabricated the $\mathrm{Ag}_{3} \mathrm{PO}_{4} / \mathrm{MoS}_{2}$ nanocomposites and revealed that the improved performance of $\mathrm{Ag}_{3} \mathrm{PO}_{4} / \mathrm{MoS}_{2}$ can be ascribed to wide spectra response, efficient charge separation and enhanced oxidation capacity. He et al. developed a two-step $\mathrm{ZnO}$-modified strategy to immobilize the catalyst on rGO sheets. The high ammonia degradation efficiency of $\mathrm{ZnO} / \mathrm{Cu} / \mathrm{rGO}$ can be attributed to the enhanced ROSs production efficiency and the activated interfacial catalytic sites. Shi et al. prepare high energy faceted $\mathrm{TiO}_{2}$ nanosheets by calcination of $\mathrm{TiOF}_{2}$ cubes. The $500^{\circ} \mathrm{C}$-calcined sample exhibits the highest photocatalytic activity for removal of acetone owing to the high energy $\mathrm{TiO}_{2}$-NSs and the surface adsorbed fluorine.

Kim et al. synthesized the nitrogen doped $\mathrm{TiO}_{2}$ by a novel plasma electrolysis method. The 0.4 at. $\% \mathrm{~N}$ doped $\mathrm{TiO}_{2}$ catalyst showed the highest photocatalytic performance. Xu et al. developed a $\mathrm{BiOCl} / \mathrm{NaNbO}_{3}$ p-n heterojunction by an in-situ method. The $\mathrm{BiOCl} / \mathrm{NaNbO}_{3}$ composites exhibited much

\section{REFERENCES}

Chen, P., Wang, H., Liu, H., Ni, Z., Li, J., Zhou, Y., et al. (2019). Directional electron delivery and enhanced reactants activation enable efficient photocatalytic air purification on amorphous carbon nitride Co-Functionalized with O/La. Appl. Catal. B Environ. 242, 19-30. doi: 10.1016/j.apcatb.2018. 09.078

Cui, W., Li, J., Sun, Y., Wang, H., Jiang, G., Lee, S., et al. (2018). Enhancing ROS generation and suppressing toxic intermediate production inphotocatalytic NO oxidation on $\mathrm{O} / \mathrm{Ba}$ co-functionalized amorphous carbon nitride. Appl. Catal. B Environ. 237, 938-946. doi: 10.1016/j.apcatb.2018.06.071

Dong, X., Li, J., Xing, Q., Zhou, Y., Huang, H., and Dong, F. (2018a). The activation of reactants and intermediates promotes the selective photocatalytic NO conversion on electron-localized Sr-intercalated g- $\mathrm{C}_{3} \mathrm{~N}_{4}$. Appl. Catal. B Environ. 232, 69-76. doi: 10.1016/j.apcatb.2018.03.054

Dong, X., Zhang, W., Sun, Y., Li, J., Cen, W., Cui, Z., et al. (2018b). Visible light induced charge transfer pathway and photocatalysis mechanism on $\mathrm{Bi}$ semimetal@defective BiOBr hierarchical microspheres. J. Catal. 357, 41-50. doi: 10.1016/j.jcat.2017.10.004

He, W., Sun, Y., Jiang, G., Huang, H., Zhang, X., and Dong, F. (2018b). Activation of amorphous $\mathrm{Bi}_{2} \mathrm{WO}_{6}$ with synchronous $\mathrm{Bi}$ metal and $\mathrm{Bi}_{2} \mathrm{O}_{3}$ coupling: photocatalysis mechanism and reaction pathway. Appl. Catal. B Environ. 232, 340-347. doi: 10.1016/j.apcatb.2018.03.047

He, W., Sun, Y., Jiang, G., Li, Y., Zhang, X., Zhang, Y., et al. (2018a). Defective $\mathrm{Bi}_{4} \mathrm{MoO}_{9} / \mathrm{Bi}$ metal core/shell heterostructure: enhanced visible light photocatalysis and reaction mechanism. Appl. Catal. B Environ. 239, 619-627. doi: 10.1016/j.apcatb.2018.08.064 enhanced photocatalytic activity attributed to the formation of p-n junction between $\mathrm{NaNbO}_{3}$ and $\mathrm{BiOCl}$ that facilitated the charge separation (Xu et al.). Ren et al. synthesized the $\mathrm{AgBr} @ \mathrm{Ag}$ modified titanium phosphate composites. The AgBr@Ag/titanium phosphate exhibited higher photocatalytic activity and the photocatalytic degradation mechanisms were proposed.

She et al. reported selective activation of saturated $\mathrm{C}-\mathrm{H}$ bond to generate the high-value-added chemicals on Ni-doped $\mathrm{CdS}$ nanoparticles. The high photocatalytic performance can be attributed to the cubic and hexagonal phases, $\mathrm{Ni}$-doping and the charge carriers separation. $\mathrm{Li}$ et al. synthesized $\mathrm{Au} / \mathrm{BiFeO}_{3}$ homojunctions via a simple method. The Au1.2-BFO showed efficient photocatalytic activity due to the hierarchical structure, SPR effect of Au particles, and the defects (Li et al.). Zhang and Liang fabricated the new 2D g- $\mathrm{C}_{3} \mathrm{~N}_{4} @ \mathrm{BiOCl} / \mathrm{Bi}_{12} \mathrm{O}_{17} \mathrm{Cl}_{2}$ by a facile approach, which showed enhanced visible light absorption and electron-hole separation efficiency and thus highly enhanced photocatalytic activity for NO removal.

At last, as the Guest Editors of this topic issue, we would like to appreciate all the authors for the contributed articles and thank for all the referees for their comments on the manuscripts. We hope that the readers will find the results in articles of this topic issue interesting and useful for their research. Finally, we appreciate the editorial staff of Frontiers in Chemistry for their work in publishing of this topic issue.

\section{AUTHOR CONTRIBUTIONS}

All authors listed have made a substantial, direct and intellectual contribution to the work, and approved it for publication.

Huo, W., Dong, X., Li, J., Liu, M., Liu, X., Zhang, Y., et al. (2019). Synthesis of $\mathrm{Bi}_{2} \mathrm{WO}_{6}$ with gradient oxygen vacancies for highly photocatalytic NO oxidation and mechanism study. Chem. Eng. J. 361, 129-138. doi: 10.1016/j.cej.2018.12.071

Li, J., Dong, X., Sun, Y., Cen, W., and Dong, F. (2018a). Facet-dependent interfacial charge separation and transfer in plasmonic photocatalysts, Appl. Catal. B Environ. 226, 269-277. doi: 10.1016/j.apcatb.2017.12.057

Li, J., Dong, X., Sun, Y., Jiang, G., Chu, Y., Lee, S., et al. (2018b). Tailoring the rate-determining step in photocatalysis via localized excess electrons for efficient and safe air cleaning. Appl. Catal. B Environ. 239, 187-195. doi: 10.1016/j.apcatb.2018.08.019

Li, J., Zhang, W., Ran, M., Sun, Y., Huang, H., and Dong, F. (2019). Synergistic integration of $\mathrm{Bi}$ metal and phosphate defects on hexagonal and monoclinic $\mathrm{BiPO}_{4}$ : enhanced photocatalysis and reaction mechanism. Appl. Catal. B Environ. 243, 313-321. doi: 10.1016/j.apcatb.2018.10.055

Li, J., Zhang, Z., Cui, W., Wang, H., Cen, W., Johnson, G., et al. (2018c). The spatially oriented charge flow and photocatalysis mechanism on internal van der waals heterostructures enhanced g- $\mathrm{C}_{3} \mathrm{~N}_{4}$. ACS Catal. 8, 8376-8385. doi: 10.1021/acscatal.8b02459

Li, X., Zhang, W., Cui, W., Sun, Y., Jiang, G., Zhang, Y., et al. (2018). Bismuth Spheres Assembled on Graphene Oxide: Directional Charge Transfer Enhances Plasmonic Photocatalysis and In Situ DRIFTS Studies. Appl. Catal. B Environ. 221, 482-489. doi: 10.1016/j.apcatb.2017.09.046

Li, X., Zhang, W., Li, J., Jiang, G., Zhou, Y., Lee, S., et al. (2019). Transformation pathway and toxic intermediates inhibition of photocatalytic NO removal on designed Bi metal@defective $\mathrm{Bi}_{2} \mathrm{O}_{2} \mathrm{SiO}_{3}$, Appl. Catal. B Environ. 241, 187-195. doi: 10.1016/j.apcatb.2018.09.032 
Wang, H., He, W., Dong, X., Wang, H., and Dong, F. (2018a). In situ FT-IR investigation on the reaction mechanism of visible light photocatalytic NO oxidation with defective g- $\mathrm{C}_{3} \mathrm{~N}_{4}$. Sci. Bull. 63,117-125. doi: 10.1016/j.scib.2017.12.013

Wang, H., Sun, Y., He, W., Zhou, Y., Lee, S., and Dong, F. (2018c). Visible light induced electrons transfer from semiconductor to insulator enables efficient photocatalytic activity on insulator-based heterojunctions. Nanoscale 10, 15513-15520. doi: 10.1039/C8NR03845G

Wang, H., Sun, Y., Jiang, G., Zhang, Y., Huang, H., Wu, Z., et al. (2018b). Unraveling the mechanisms of visible light photocatalytic NO purification on earth-abundant insulator-based core-shell heterojunctions. Environ. Sci. Technol. 52, 1479-1487. doi: 10.1021/acs.est.7b05457

Wang, H., Zhang, W., Li, X., Li, J., Cen, W., Li, Q., et al. (2018d). Highly enhanced visible light photocatalysis and in situ FT-IR studies on Bi metal@defective BiOCl hierarchical microspheres. Appl. Catal. B Environ. 225, 218-227. doi: 10.1016/j.apcatb.2017.11.079
Xiong, T., Wang, H., Zhou, Y., Sun, Y., Cen, W., Huang, H., et al. (2018). KCl-mediated dual electronic channels in layered $\mathrm{g}-\mathrm{C}_{3} \mathrm{~N}_{4}$ for enhanced visible light photocatalytic NO removal. Nanoscale 10, 8066-8074. doi: 10.1039/C8NR01433G

Conflict of Interest Statement: The authors declare that the research was conducted in the absence of any commercial or financial relationships that could be construed as a potential conflict of interest.

Copyright (C) 2019 Dong, Zhang and Zhang. This is an open-access article distributed under the terms of the Creative Commons Attribution License (CC BY). The use, distribution or reproduction in other forums is permitted, provided the original author(s) and the copyright owner(s) are credited and that the original publication in this journal is cited, in accordance with accepted academic practice. No use, distribution or reproduction is permitted which does not comply with these terms. 